\title{
HISTORICAL SEISMICITY AND RATES OF CRUSTAL DEFORMATION ALONG THE MARGINS OF THE ORDOS BLOCK, NORTH CHINA
}

\author{
By. S. G. Wesnousky*, L. M. Jones†, C. H. Scholz $\ddagger$, and QIDong Deng
}

\begin{abstract}
Earthquakes in China show an empirical relation between seismic moment $\left(M_{0}\right)$ and the areal distribution of Modified Mercalli intensities VI and VIII $\left(\log M_{0}=\right.$ $16.66+0.91 \log A^{v i \prime \prime}$ and $\log M_{0}=14.35+1.16 \log A^{v \prime}$, where $A$ and $M_{0}$ are measured in squared kilometers and Newton-meter, respectively). The empirical relations may be used to estimate $M_{0}$ for historical earthquakes in China to within a factor of three, on average, when sufficient isoseismal data exist. This observation and an extensive collection of isoseismal maps are used to estimate $\boldsymbol{M}_{0}$ for large earthquakes that occurred along the margins of the Ordos block during the last $\mathbf{7 0 0} \mathrm{yr}$. Focal parameters of the historical events are inferred from the orientation and displacements across Quaternary faults. Average rates of crustal deformation are then estimated from the 700-yr historical record with formulas that relate the occurrence rate of seismic moment in a region to rates of crustal strain. The Shanxi and northern Ningxia graben systems are situated along the eastern and northwestern edges of the Ordos block, respectively. Normal faults in the two systems trend northeasterly and are characterized by a component of right-lateral slip. The deformation resulting from slip during earthquakes in each of the respective fault systems is estimated at about 0.5 to $1.0 \mathrm{~mm} / \mathrm{yr}$ of both right-lateral shear and north by northwest extension. The Weihe graben system bounds the southern edge of the Ordos block, strikes easterly and conjugate to the Shanxi and northern Ningxia fault systems, and exhibits left-lateral normal fault displacements. The average rate of deformation across Weihe is described by about $1.0 \mathrm{~mm} / \mathrm{yr}$ of north by northwest extension and $1.5 \mathrm{~mm} / \mathrm{yr}$ left-lateral east-west shear. The Hetao fault system delineates the northern edge of the Ordos block and displays Quaternary faults similar in orientation and mechanism to that observed in Weihe. Although mapped faults in Hetao exhibit evidence of Quaternary displacement, crustal deformation rates are not estimated because there exists no historical record of large earthquakes in the area. In southern Ningxia, at the southwest boundary of the Ordos block, deformation occurs by slip on left-lateral strike-slip faults oriented in an easterly azimuth and thrust faults with strikes ranging from southeast to south. The average deformation rate in southern Ningxia is found to be about $4.0 \mathrm{~mm} / \mathrm{yr}$ of east by northeast contraction and $10.0 \mathrm{~mm} / \mathrm{yr}$ of left-lateral shear. Deformation of each of the fault systems is consistent with a regional compressive stress that trends northeast and results in an average of about $3.0 \mathrm{~mm} / \mathrm{yr}$ each of contraction at $\mathrm{N} 70^{\circ} \mathrm{E}$ and extension of $\mathrm{N} 160^{\circ} \mathrm{E}$ across the entire region. Inasmuch as uncertainties in estimates of $M_{0}$ for historical earthquakes are about a factor of three, a similar uncertainty is attached to rates of crustal strain determined in this manner.
\end{abstract}

\section{INTRODUCTION}

Estimates of the component of crustal deformation that occurs as slip on faults determined from instrumental records of seismicity are associated with large uncer-

* Present address: Seismological Laboratory, California Institute of Technology, Pasadena, California 91125 .

† Present address: U.S. Geological Survey, Seismological Laboratory, California Institute of Technology, Pasadena, California 91125.

$\ddagger$ Also of the Department of Geological Sciences, Columbia University. 
tainties when the records are short with respect to the repeat time of large earthquakes in a region. Information describing historical seismicity can be used to reduce these uncertainties. A systematic relation between seismic moment $\left(M_{0}\right)$ and the areal distribution of seismic intensity has been observed in Japan and in the United States (Hanks et al., 1975; Herrmann et al., 1978; Wesnousky et al., 1982). The correlation between the two parameters provides a simple and valuable tool to estimate the seismic moment of historical earthquakes. We gather published data and examine the relation between $M_{0}$ and felt area of Modified Mercalli (MM) intensities VI and VIII for earthquakes in China. The resulting relations are used

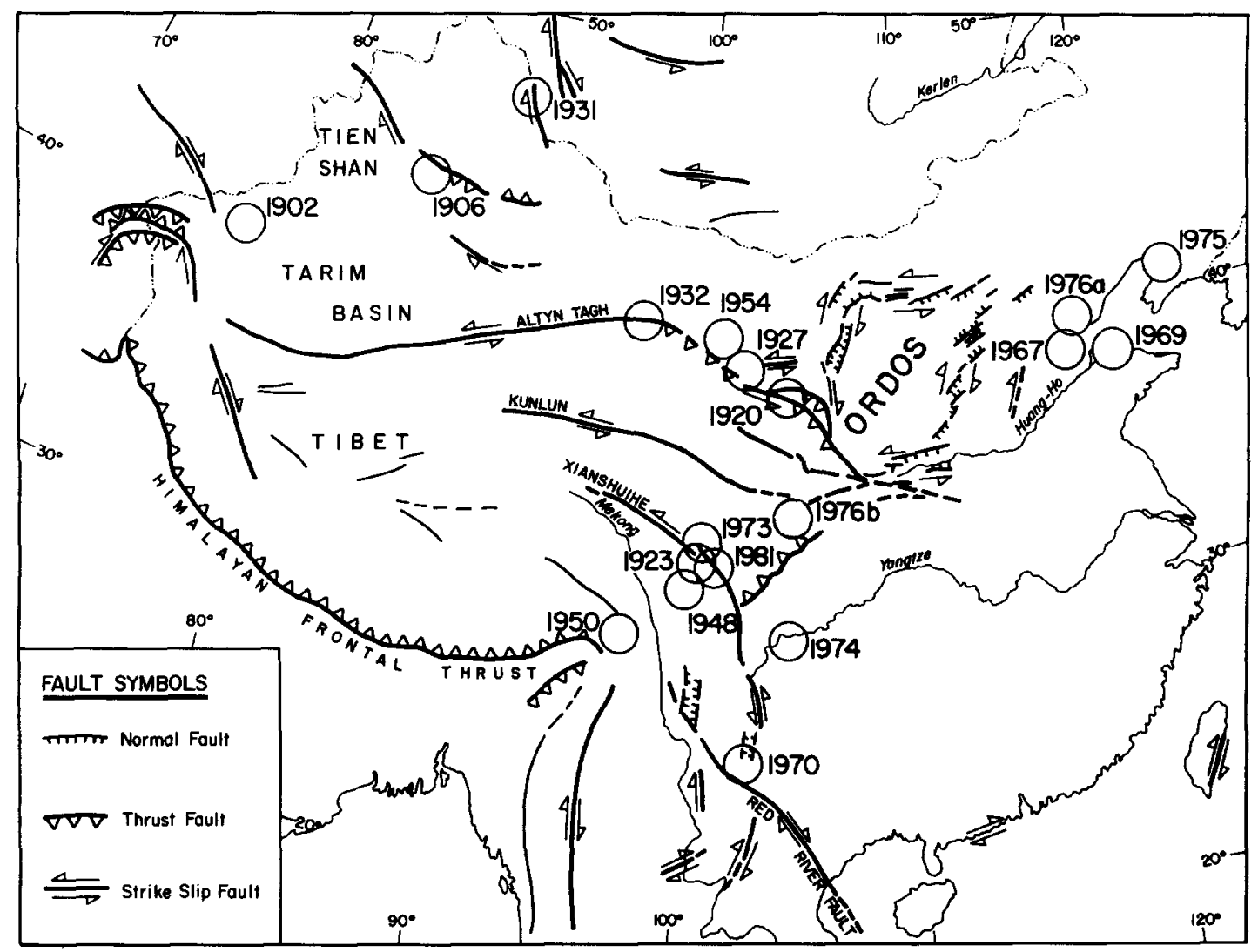

FIG. 1. Regional tectonic map of China adapted from Tapponnier and Molnar (1977) showing location of Ordos block. Epicenters (open circles) and dates of earthquakes used to establish relation between seismic moment and areal distribution of intensity are also shown.

to estimate the $M_{0}$ of large $(M>6.5)$ historical earthquakes that occurred along the boundaries of the Ordos block in North China (Figures 1 and 2) during the last $700 \mathrm{yr}$. Focal parameters of the historical events are inferred from the orientation and displacement of mapped Quaternary faults in the area. Formulas relating seismic moment to crustal strain (Kostrov, 1974; Molnar, 1983) are then utilized to estimate the rate of crustal deformation that takes place as slip on faults along the margins of the Ordos block. This simple exercise underscores the importance of historical seismicity in crustal deformation studies, provides some quantitative constraint on present rates of deformation around the Ordos block, and further allows us to compare the relationship between $M_{0}$ and the areal distribution of seismic intensity in China to that observed in Japan and the United States. 
We chose to examine the Ordos fault block because it has the longest historical record of seismicity in existence. Xian, the capital of China from 221 B.C. to 960 A.D., and Beijing, the present capital, are located adjacent to the crustal block (Figure 2). The historical record of seismicity in this region is over $3000 \mathrm{yr}$ long (Chinese Academy of Science, 1970; Lee et al., 1976). We limit our attention to the period since 1278 A.D., the start of the Yuan dynasty when Beijing was established as the capital of China. It is for this period that the historical record for this region appears relatively complete for large earthquakes of $M$ greater than about 7.

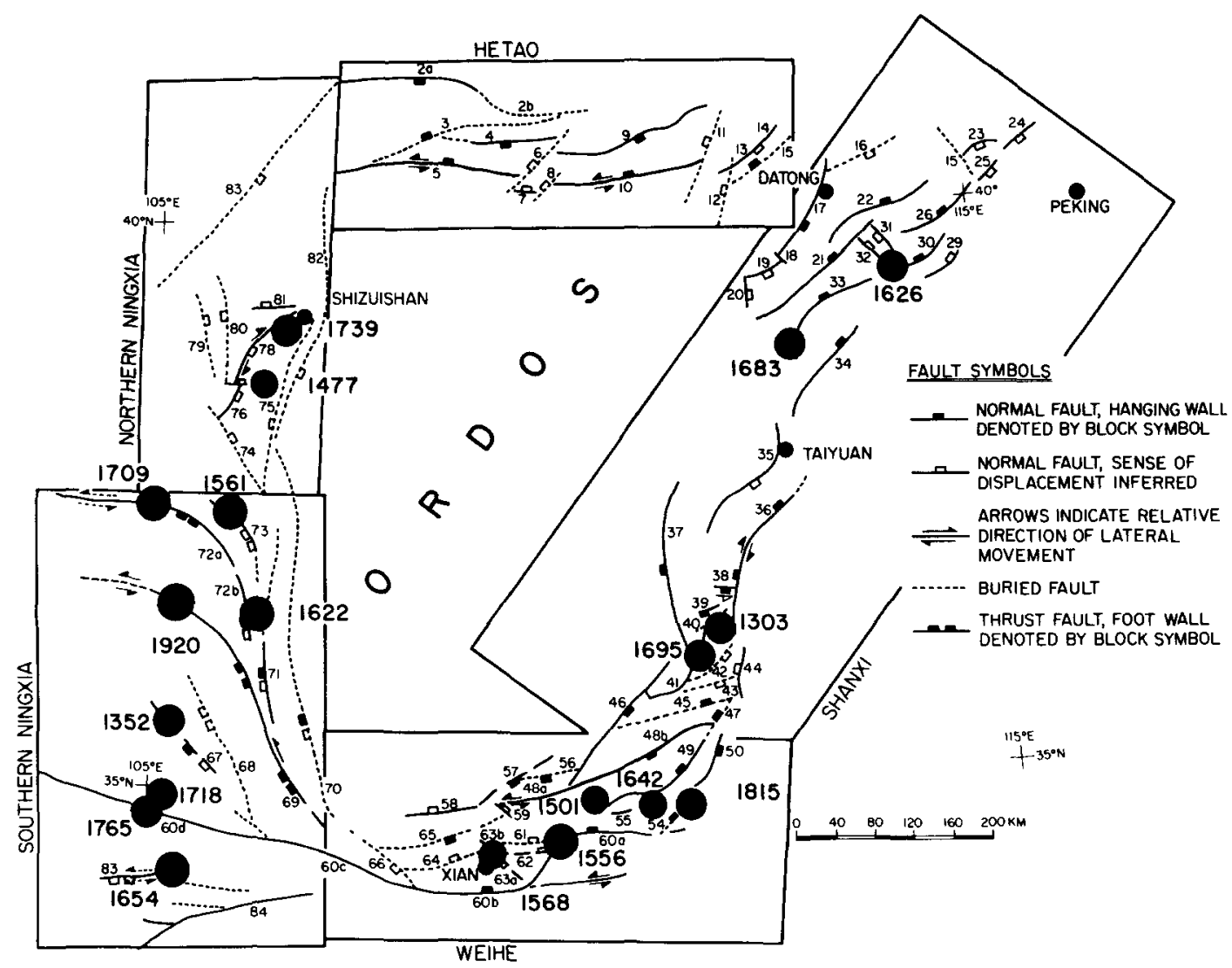

FIG. 2. Locations and dates of major earthquakes during the last $700 \mathrm{yr}$ and distribution of Quaternary faults along the margins of the Ordos block. Boxes outline the areal extent of the regions used in deformation analyses.

The margins of the Ordos fault block are one of the most seismically active regions in northern China. The epicentral distribution of large $(M>6.5)$ earthquakes recorded during the last $700 \mathrm{yr}$ is plotted in Figure 2. The distribution of Quaternary faults is also shown. The Ordos block appears aseismic with all of the seismicity located along the edges of the block. In accord with the observations of seismicity, geologic data indicate that the Ordos block has not experienced deformation since Mesozoic time (Tapponnier and Molnar, 1977). For the most part, the Ordos block is surrounded by a series of elongate depressions that are bounded by steep normal faults that exhibit evidence of Quaternary movement (Tapponnier and Molnar, 1977; Deng et al., 1984). The exception to this observation occurs along the southwestern edge of the block. Faults in this area appear to be predominantly strike-slip and thrust with orientations and displacements that indicate the principal 
component of horizontal stress is compressive in a northeasterly direction (Tapponnier and Molnar, 1976; Deng et al., 1984; Figure 2). The general orientation of the bounding graben structures, in contrast, implies crustal extension in a northwesterly direction during the Quaternary.

The Hetao and Weihe graben systems (Figure 2) mark the northern and southern boundaries of the Ordos block, respectively. The normal faults that comprise each system show a left-lateral component of slip, and strike in an easterly direction. The northwestern and eastern edges of the Ordos block are bounded by normal faults that form the northern Ningxia and Shanxi graben systems, respectively (Figure 2). Normal faults in northern Ningxia and Shanxi show, in contrast to Hetao and Weihe, a component of right-lateral displacement. The northern Ningxia, Weihe, and Hetao fault systems commenced development in early Tertiary time whereas the Shanxi fault system is apparently younger, developing since the late Tertiary (Deng et al., 1973, 1980, 1982).

A series of studies employing LANDSAT imagery, earthquake locations, and field observations show that the mode of faulting adjacent to the Ordos block is consistent with a northeast-trending regional compressive stress imposed by the collision and subsequent penetration of India into Eurasia (Molnar and Tapponnier, 1975, 1977a, b; Tapponnier and Molnar, 1976, 1977; Deng et al., 1984). The distribution of the four graben systems may, at least in part, be interpreted as representing a set of conjugate shear fractures in the earth's crust, as evidenced by the conjugate orientation of the four graben systems and the components of lateral displacement observed for each system (Deng, 1984; Deng and Fan, 1980). Tapponnier and Molnar (1977) further observe that the Ordos block is situated at the eastern end of a major left-lateral fault system and that "the associated fault system may have originated much as tension cracks originate at the end of shear cracks at a smaller scale."

\section{ANALYSIS}

\section{The seismic moment tensor}

The seismic moment tensor $\left(M_{i j}\right)$ is a quantitative measure of the strength of an earthquake and the deformation resulting from its occurrence (e.g., Aki, 1966; Aki and Richards, 1980). For shearing on a fault, the scalar value of seismic moment $\left(M_{0}\right)$ is $\mu u A$, where $\mu$ is the shear modulus, $u$ is the average slip on the fault, and $A$ the fault area. $M_{i j}$ for a shear dislocation can be completely described when the strike, dip, and rake of the fault are known in addition to $M_{0}$, and may be expressed as

$$
M_{i j}=M_{0}\left(b_{i} n_{j}+b_{j} n_{i}\right)
$$

where $b$ and $n$ are unit vectors in the direction of slip and normal to the fault plane, respectively (Gilbert, 1970). Kostrov (1974) showed that the mean rate of irrotational strain, $\epsilon_{i j}=\frac{1}{2}\left(\partial \dot{u}_{i} / \partial x_{j}+\partial \dot{u}_{j} / \partial x_{i}\right)$, of a seismogenic volume $V$ resulting from earthquake dislocations is proportional to the sum of seismic moment tensors of all earthquakes occurring in that volume $V$ in time $T$

$$
\dot{\epsilon}_{i j}=\frac{1}{2 \mu V T}\left(\sum_{x=1}^{N} M_{i j}^{(x)}\right) .
$$


Equation (2) is appropriate for regions characterized by a set of conjugate faults. Molnar (1983) recently presented a modification of Kostrov's (1974) formula to determine the average rate of finite (rotational) strain, $\dot{\epsilon}_{i j}^{*}=\partial \dot{u_{i}} / \partial x_{j}$, for a region characterized by a set of faults that are not necessarily conjugate but rather may show a similar sense of offset and strike

$$
\dot{\epsilon}_{i j}^{*}=\frac{1}{\mu V T}\left(\Sigma M_{i j}^{*}\right)
$$

where $\Sigma M_{i j}^{*}$ is the sum of asymmetric moment tensors, $M_{i j}^{*}=M_{0} b_{i} n_{j}$, for earthquakes in the volume being considered. We use (2) and (3) with historical seismicity data to estimate rates of crustal extension, contraction, and shear movement within the regions bounding the Ordos block.

\section{Correlation of seismic moment to the areal distribution of seismic intensity}

Molnar and Deng (1984) estimated the seismic moments of the major earthquakes that have occurred in central and eastern Asia during the last $80 \mathrm{yr}$. Their estimates are based primarily on independent estimates of fault length $l$ and average displacement $u$, and less so on measurements of seismic wave amplitudes. Isoseismal maps of most of the events that are located in China are available in the Atlas of Isointensity Maps for Chinese Earthquakes (Chinese Area of Earthquake Intensity Study Group, 1976). The epicentral distribution of the earthquakes studied by Molnar and Deng (1984) for which isoseismal maps are available is shown in Figure 1. For each of the events, the areal distribution $(A)$ of both MM intensity VI and VIII (as approximated by an ellipse around the epicentral region) is compared to the estimated value of $M_{0}$. The results are presented in Figure 3 (A and B) and further detailed in Table 1 . Of the 12 data pairs plotted for intensity VI, all but two fall within a factor of three of the value of moment predicted by the relation drawn in Figure 3A. Similarly, all but 3 of the 16 data pairs for intensity VIII are estimated to within a factor of three of the value of seismic moment predicted by the relation shown in Figure 3B. Inasmuch as uncertainties in most estimates of $M_{0}$ are a factor of two to three, Figure 3 (A and B) suggests that $M_{0}$ may, on average, be estimated to within a factor of three for large historical events when sufficient seismic intensity data exist.

\section{Seismic moment tensor of historical earthquakes}

Isoseismal maps for the large $(M \geqq 6.5)$ events that occurred along the margins of the Ordos block during the last $700 \mathrm{yr}$ are published in the Catalogue of Chinese Earthquakes (Chinese Academy of Science, 1970) and the Atlas of Isointensity Maps for Chinese Earthquakes (Chinese Area of Earthquake Intensity Study Group, 1976). The areal distribution of MM intensity VI and VIII for each event is approximated by drawing ellipses around the epicentral region that correspond to the respective isoseismals. $M_{0}$ for each of the earthquakes is approximated using the relations in Figure 3 . The results are listed in Table 2.

The location of the historical earthquakes, as evidenced by the distribution of isoseismals, strongly suggests that the events occurred on the faults that are now mapped (Figure 2). Data describing the orientation and displacements across the Quaternary faults can be used to further estimate the strike, dip, and rake and, hence, the complete seismic moment tensor of the historical earthquakes. We infer 

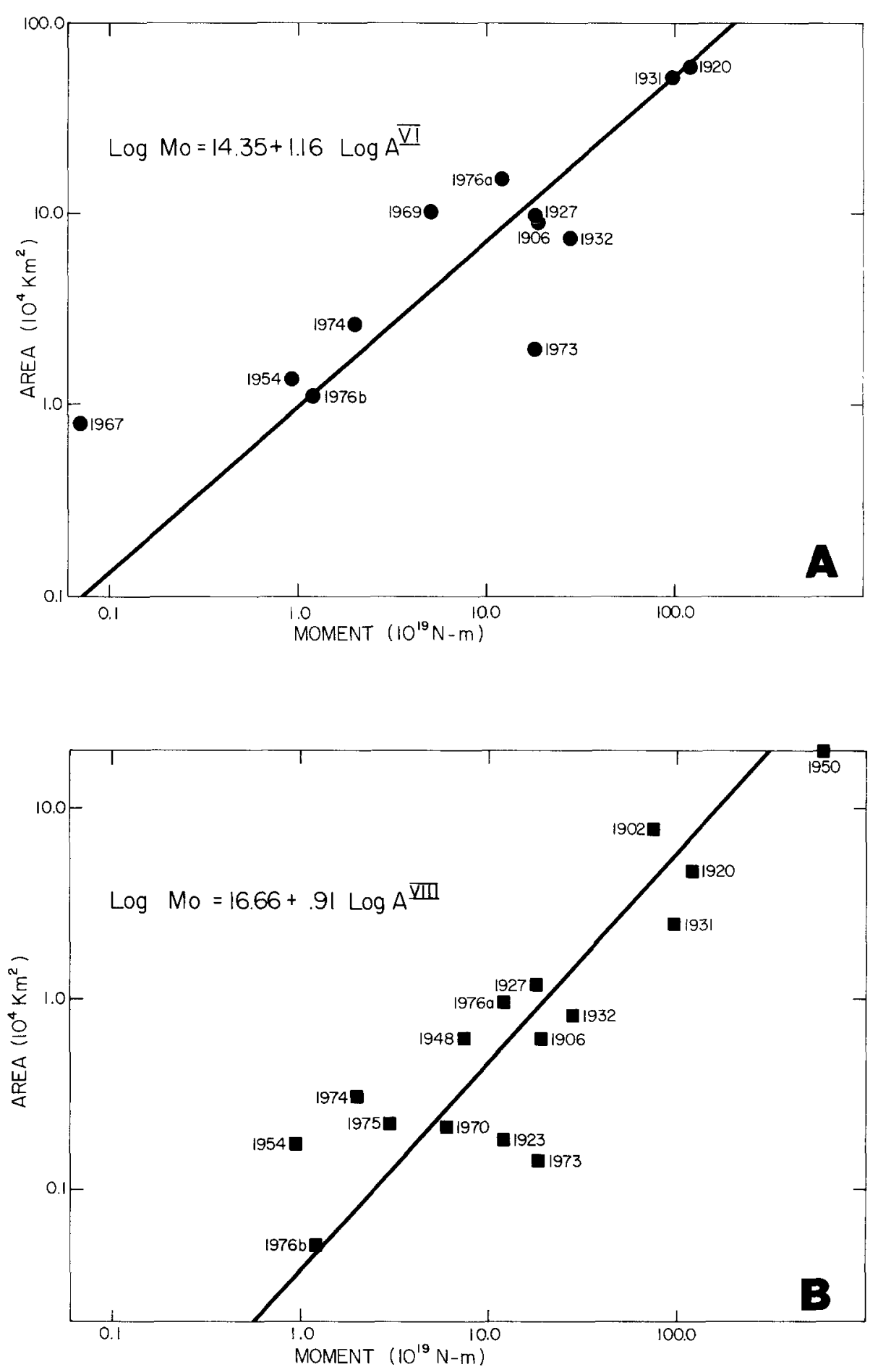

FIG. 3. Seismic moment versus the areal distribution of MM intensity (A) VI and (B) VIII for earthquakes in China. Dates correspond to those listed in Figure 1 and Table 1. 
that the displacement in historical earthquakes was of the same sense as exhibited by nearby Quaternary faults. Our primary references for this aspect of the work are Tapponnier and Molnar (1977), field observations in Shanxi and Weihe (Deng, 1984; Deng et al., 1973, 1980), a recent account of field work along the southwest and western boundaries of the Ordos block by Deng et al. (1984), and the Seismotectonic Map of the People's Republic of China (Institute of Geology, 1979). The assignment of focal parameters to each of the historical earthquakes is summarized in Table 2 and will be further detailed below.

Errors in either the assessment of the scalar value of $M_{0}$ or the assignment to the focal parameters of strike, dip, and rake for the historical earthquakes will result in uncertainties in the evaluation of crustal strain rates, when determined with equations (2) and (3). Uncertainty in the estimate of $M_{0}$ for the historical events is

TABLE 1

Seismic Moment Versus Areal Distribution of Seismic Intensity for Recent large EARTHQUAKES IN CHINA

\begin{tabular}{clccccc}
\hline \multirow{2}{*}{$\begin{array}{c}\text { Date } \\
\text { (yr. m.d.) }\end{array}$} & \multicolumn{2}{c}{ Location } & $\begin{array}{c}M_{0^{*}}^{*} \\
\left(\times 10^{10} \mathrm{~N}-\mathrm{m}\right)\end{array}$ & $\begin{array}{c}\text { Area } \\
\left(\times 10^{3} \mathrm{~km}^{2}\right)\end{array}$ & $\begin{array}{c}\text { Area } \\
\left(\times 10^{3} \mathbf{k m}^{2}\right)\end{array}$ \\
\cline { 2 - 3 } 1902.08 .22 & North & East & 75 & - & 76 \\
1906.12 .22 & 43.5 & 77 & 75 & 19 & 78 & 6.1 \\
1920.12 .20 & 36.62 & 105.40 & 120 & 583 & 46.7 \\
1923.03 .24 & 30.92 & 100.26 & 12 & - & 1.8 \\
1927.05 .23 & 38.05 & 102.37 & 18 & 97.4 & 11.8 \\
1931.08 .10 & 46.89 & 90.06 & 97 & 518 & 24.4 \\
1932.12 .25 & 39.70 & 96.70 & 28 & 71.6 & 8.1 \\
1948.05 .25 & 30.21 & 99.88 & 7.4 & - & 6.2 \\
1950.08 .15 & 28.38 & 96.76 & 800 & - & 212 \\
1954.02 .11 & 38.94 & 101.36 & 0.93 & 13.7 & 1.73 \\
1967.03 .27 & 38.56 & 116.61 & 0.07 & 8.0 & - \\
1969.07 .28 & 38.43 & 119.47 & 5.0 & 100 & - \\
1970.01 .04 & 24.14 & 102.50 & 6.0 & - & 2.1 \\
1973.02 .06 & 31.40 & 100.58 & 18.0 & 19.6 & 1.4 \\
1974.05 .10 & 28.24 & 104.02 & 2.0 & 2.64 & 0.3 \\
1975.02 .04 & 40.65 & 122.8 & 2.8 & - & 2.2 \\
1976.07 .27 & 39.57 & 117.98 & 12.0 & 150 & 9.7 \\
1976.08 .16 & 32.9 & 104.1 & 1.2 & 10.7 & 0.5 \\
\hline
\end{tabular}

${ }^{*}$ From Molnar and Deng (1983).

considered to be on average a factor of three, based upon the scatter of data in Figure 3. The assignment of focal parameters to historical earthquakes is founded on the assumption that the sense of slip during the earthquakes was the same as that observed on nearby Quaternary faults. This assumption seems valid but, nonetheless, there remains an uncertainty involved in assessing the strike, dip, and rake of the Quaternary faults since detailed geologic studies are not available for much of the region. The strike of Quaternary faults is readily obtained from available maps (Institute of Geology, 1979; Deng et al., 1984). Constraints on the parameters dip and rake are generally less certain. Published geologic data specific to the fault are used when possible. In other cases, the sense of displacement is inferred from knowledge of offsets across nearby faults in the area, or from other information concerning the regional style of deformation. Errors in either the dip or rake values we assign to the historical earthquakes will correspondingly produce errors in the 
computed components of the moment tensor and, hence, the strain tensor. Our observations show that changes as great as $\pm 15^{\circ}$ in both the dip and rake components yield changes in our estimates of the primary components of horizontal deformation that are generally small compared to the uncertainty attached to our estimates of $M_{0}$. The source parameters given for the historical earthquakes should thus be considered as best estimates and not exact. Similarly, the rates of crustal deformation we compute with this data set should be viewed as estimates that are certain to no better than a factor of three.

TABLE 2

Estimated Fault Parameters of Historical Earthquakes AROUND THE ORDOS BLOCK

\begin{tabular}{|c|c|c|c|c|}
\hline \multirow{2}{*}{$\begin{array}{c}\text { Date } \\
\text { (ys. m.d.) }\end{array}$} & \multirow{2}{*}{$\begin{array}{c}M_{0} \\
\left(\times 10^{19} \mathrm{~N}-\mathbf{m}\right)\end{array}$} & \multicolumn{3}{|c|}{ Fault Parameters* } \\
\hline & & Strike & Dip & Rake \\
\hline \multicolumn{5}{|c|}{ Shanxi } \\
\hline 1303.09 .17 & 11.8 & 200.0 & 60.0 & -160.0 \\
\hline 1626.06 .28 & 8.1 & 220.0 & 60.0 & -120.0 \\
\hline 1683.11 .22 & 14.2 & 200.0 & 60.0 & -160.0 \\
\hline 1695.05 .18 & 8.1 & 90.0 & 60.0 & 30.0 \\
\hline \multicolumn{5}{|c|}{ Weihe } \\
\hline 1501.01 .19 & 3.3 & 230.0 & 60.0 & -30.0 \\
\hline 1556.01 .23 & 66.1 & 270.0 & 60.0 & -30.0 \\
\hline 1568.05 .15 & 1.8 & 270.0 & 60.0 & -30.0 \\
\hline 1642.06 .30 & 0.73 & 230.0 & 60.0 & -30.0 \\
\hline 1815.10 .23 & 4.2 & 230.0 & 60.0 & -30.0 \\
\hline \multicolumn{5}{|c|}{ Northern Ningxia } \\
\hline 1477.05 .13 & 0.67 & 30.0 & 75.0 & -150.0 \\
\hline 1739.01 .03 & 15.9 & 30.0 & 75.0 & -150.0 \\
\hline \multicolumn{5}{|c|}{ Southern Ningxia } \\
\hline 1352.04 .18 & 1.9 & 130.0 & 45.0 & 90.0 \\
\hline 1561.07 .25 & 6.9 & 145.0 & 30.0 & 90.0 \\
\hline 1622.10 .25 & 34.2 & 180.0 & 45.0 & 90.0 \\
\hline 1654.07 .21 & 42.7 & 105.0 & 90.0 & 0 \\
\hline 1709.10 .14 & 17.8 & 295.0 & 30.0 & 30.0 \\
\hline 1718.06 .19 & 8.9 & 105.0 & 90.0 & 0 \\
\hline 1765.09 .02 & 4.0 & 105.0 & 90.0 & 0 \\
\hline 1920.12 .16 & 120.0 & 115.0 & 90.0 & 0 \\
\hline
\end{tabular}

* Values assigned according to conventions used by Aki and Richards $(1980)$.

The regions adjacent to the Ordos block can be divided into four distinct regions based upon the distribution and style of active faulting (Figure 2). For convenience of discussion, the seismicity of each of the regions is considered separately.

Hetao. The northernmost region is situated in a sparsely populated portion of Inner Mongolia. The north bounding faults of the Hetao graben system (faults 2, 
4, and 9 in Figure 2) show predominantly normal slip whereas the basin bounding faults to the south (faults 5 and 10 in Figure 2) further exhibit a clear component of left-lateral motion, evidenced by offset streams (Deng, 1984). We necessarily ignore this region because there is no record of large earthquakes. It is uncertain whether the lack of seismicity is real or results from an incomplete historical record. The presence of Quaternary faults, however, and the occurrence of several moderate earthquakes during the last $20 \mathrm{yr}$ suggest that the latter is the more likely case.

Southern Ningxia. Eight large events occurred in this region during the last 700 yr, including the great Haiyuan earthquake of 1920 . The 1920 event produced leftlateral rupture along a $220-\mathrm{km}$ segment of the Haiyuan fault (fault 69 of Figure 2), striking about $115^{\circ}$ from north (Molnar and Deng, 1984). Surface displacements ranging to $8 \mathrm{~m}$ are consistent with the seismic moment of $1.2 \times 10^{21} \mathrm{~N}-\mathrm{m}$ determined by Deng et al. (1984) from amplitude spectral density measurements of 100 -sec surface waves. The 1561 and 1709 events are located near thrust faults that dip to the southwest (Deng et al., 1984). Accordingly we assign each event a dip of $30^{\circ}$ and a strike similar to the nearest adjacent mapped Quaternary fault. Slip during the 1561 event is assumed to be pure thrust. Slickensides observed on a fault adjacent to the 1709 earthquake suggest that this event may have had a predominantly leftlateral component of slip. We assume a rake value of $30^{\circ}$ for the 1709 event. Mapped faults adjacent to the 1622 epicenter strike north and are of an uncertain sense of movement (Deng et al., 1984). We assume that the 1622 event was reverse with a strike and dip of $180^{\circ}$ and $45^{\circ}$, respectively. This interpretation is consistent with the stress regime implied by displacements recorded during the 1920 Haiyuan earthquake which occurred nearby. Mapped faults northeast and southwest of the 1352 event show thrust motion and strike southeast. We assume a similar sense of displacement for the 1352 event. The remaining earthquakes of 1654, 1718, and 1765 occur in the southern portion of this region near a fault system that trends easterly. The similarity in strike of the system with major left-lateral faults farther to the east, and the linearity of mapped faults, is consistent with left-lateral motion. We thus assume that these events produced left-lateral slip on faults striking $105^{\circ}$ east of north.

Northern Ningxia. The predominant style of faulting in northern Ningxia takes place on normal faults that show a comparable, if not larger right-lateral strike-slip component (Deng et al., 1979, 1980, 1984; Deng and You, 1984). A section of the Great Wall of China, constructed in the 15 th century, crosses this region near Shizuishan city and is offset by a strand of fault 78 (Figure 2) that trends $\mathrm{N} 30^{\circ} \mathrm{E}$. Displacement of the wall at one locality is normal with a component of right-lateral strike slip motion. The horizontal displacement is about $1.45 \mathrm{~m}$, and the vertical offset is about $0.95 \mathrm{~m}$ (Deng et al., 1979). Trenching adjacent to this site further indicates a steep $\left(\sim 70^{\circ}\right)$ fault dip (Liao and Pan, 1982). Mapped fault traces adjacent to the epicenters of the two historical events that have occurred in this region trend at about $\mathrm{N} 30^{\circ} \mathrm{E}$. We assume the sense of movement during each of these events is similar to that observed along the Great Wall.

Shanxi Graben system. The Shanxi graben system extends nearly $800 \mathrm{~km}$ in a northeasterly direction. The system is characterized by a series of elongated basins filled with Quaternary alluvium and bordered by steep normal faults, especially on their southeastern sides (Tapponnier and Molnar, 1977; Deng, 1984). The normal faults generally trend northeast (Tapponnier and Molnar, 1977) and exhibit varying degrees of right-lateral motion (Deng, 1984; Deng et al., 1973). Four major events 
are recorded in Shanxi during the last 700 yr. The 1303 and 1683 epicenters are adjacent to Quaternary faults that strike about $\mathrm{N} 20^{\circ} \mathrm{E}$, dip steeply to the northeast, and show a greater component of strike slip than normal displacement (Deng et al., 1973). We assume a rake and dip of $60^{\circ}$ and $-160^{\circ}$, respectively. A similar mechanism is assigned to the 1626 event, except that the strike is taken to be more northeasterly at $\mathrm{N} 40^{\circ} \mathrm{E}$. The trend of the 1695 Liajen earthquake isoseismal is elongated in an easterly direction, in contrast to the northeast elongation of isoseismals for the 1303,1683 , and 1626 events. It is felt that this event likely occurred on an east-west trending graben fault similar to fault 38 (Figure 2). Fault 38 dips steeply to the south $\left(\sim 60^{\circ}\right)$ and shows predominantly left-lateral slip (Deng et al., 1973). A similar sense of displacement is inferred for the 1695 event.

Weihe. The Weihe graben system is comprised of a set of east-trending normal faults that generally exhibit steep dips and a component of left-lateral offset (Deng, 1984). The great 1556 event occurred on fault 60a (Deng et al., 1973). The strike and dip of this earthquake are taken as $\mathrm{N} 90^{\circ} \mathrm{W}$ and $60^{\circ}$, respectively, similar to offsets observed on fault 60a (Deng et al., 1973). Unpublished field reports of Chinese geologists suggest that the strike-slip component of the 1556 event was larger than the normal component of displacement. On this basis, we assume a rake of $-30^{\circ}$ for the 1556 event. The fault parameters of the 1568 event are inferred to be the same as those assigned to the 1556 event. The 1501, 1642, and 1815 earthquakes occurred in the area where the easterly trend of the Weihe fault system bends northeasterly into the Shanxi graben system. We assume these events were of the same mechanism as inferred for the 1556 event but cannot rule out the possibility that the events produce a right-lateral component of slip similar to mapped Quaternary faults in the Shanxi fault system.

\section{Computations}

Input. We initially treat the northern Ningxia, southern Ningxia, Weihe, and Shanxi areas (Figure 2) separately. Subsequently, we examine the deformation of the region when treated as a whole. The areal dimensions of the deforming volume $V$ for each of the regions shown in Figure 2 are chosen as follows: northern Ningxia, $425 \mathrm{~km}$ by $210 \mathrm{~km}$; southern Ningxia, $475 \mathrm{~km}$ by $300 \mathrm{~km}$; Weihe, $200 \mathrm{~km}$ by 475 $\mathrm{km}$; and Shanxi, $800 \mathrm{~km}$ by $325 \mathrm{~km}$. The thickness of the seismogenic volume for each region is placed at $20 \mathrm{~km}$, as evidenced by the common limit of earthquake foci to this depth in northeast China (Molnar and Deng, 1984). The seismic moment tensors of earthquakes in each region (Table 2) are thus summed and used with equation (3) to define the strain rate tensor $\dot{\epsilon}_{i j}^{*}$ of each region. The complete tensor $\dot{\epsilon}_{i j}^{*}$ is provided for each area considered, although discussion is primarily concerned with the horizontal components of deformation. The movement represented by each component of the strain tensor $\dot{\epsilon}_{i j}^{*}$ is shown for reference in Figure 4. Multiplication of the horizontal components of the strain rate tensor by the appropriate distance across the deforming regions yields estimates of the horizontal components of crustal extension, contraction, and shear displacement. The results of the analyses are described below and, for reference, schematically illustrated in Figure 5. Each of the regions analyzed is denoted by a box in Figure 5 . The sense of displacement across each region is shown by arrows (contraction and extension) and half-sided arrows (shear). Rates of displacement are given adjacent to the arrows in millimeters/year. 


\section{RESULTS}

Southern Ningxia. The average rate of seismic moment release, $\dot{M}_{0}$, computed from the 700-yr historical record is $3.4 \times 10^{18} \mathrm{~N}-\mathrm{m} / \mathrm{yr}$. Conversion of the seismic moment rates to strain with equation (3) yields

$$
\dot{\epsilon}_{i j}^{*}=\left[\begin{array}{ccr}
8.8 & 3.5 & -0.5 \\
-24.3 & -12.6 & -1.0 \\
-0.05 & 2.8 & 3.8
\end{array}\right] \times 10^{-9} / \mathrm{yr} .
$$

The dominant mode of deformation is a left-lateral shear of about $-24.3 \times 10^{-9}$ / $\mathrm{yr}$, corresponding to about $11 \mathrm{~mm} / \mathrm{yr}$ of left-lateral displacement across the region. This is a consequence of assigning the largest earthquakes in the region left-lateral

\author{
$(1,1)$ \\ North and South sides \\ Move apart (North- \\ South Extension)
}

\author{
$(1,2)$ \\ East side moves North \\ Relative to West \\ (Left-lateral)
}

\section{$(1,3)$}

Bottom moves North Relative to top

\section{$(2,3)$}

Bottom moves East Relative to top
North moves East

Relative to South

(Right-lateral)
East and West sides

Moves apart

(East-West Extension)
$(3,1)$

North moves down

Relative to South

$$
(3,2)
$$

East moves down

Relative to West
$(3,3)$

Bottom Moves apart

from top

(Vertical thickening)

Fig. 4. Deformation described by each component of the strain tensor $\epsilon_{i j}^{*}$.

strike-slip mechanisms on faults that trend easterly. The results also indicate northsouth extension $\left(\dot{\epsilon}_{11}^{*}=8.8 \times 10^{-9} / \mathrm{yr}\right)$ and east-west contraction $\left(\dot{\epsilon}_{22}^{*}=-12.6 \times 10^{-9} /\right.$ $\mathrm{yr})$. This is equivalent to about $4.0 \mathrm{~mm} / \mathrm{yr}$ of both north-south extension and eastwest contraction. The mechanisms assigned to all historical events in this region are consistent with a horizontal compressive stress that trends northeast and, hence, the relatively large value of east-west shortening is reasonable. The north-south extension is primarily a result of left-lateral slip on faults striking to the southeast, as observed for the 1920 Haiyuan earthquake. The positive component of $\epsilon_{33}^{*}=3.8$ $\times 10^{-9} / \mathrm{yr}$ indicates crustal thickening, consistent with the occurrence of reverse faulting, equivalent to about $0.1 \mathrm{~mm} / \mathrm{yr}$ of thickening over the $20-\mathrm{km}$-thick volume. Changing either or both the dip and rake assigned to all the events yields changes in the horizontal components of deformation of less than 15 per cent, except for the small $\dot{\epsilon}_{12}$ component where such changes result in variations of up to 40 per cent. 
Northern Ningxia. The seismic moment release from the two events averaged over the last $700 \mathrm{yr}$ yields a moment release rate of $\dot{M}_{0}=2.4 \times 10^{17} \mathrm{~N}-\mathrm{m} / \mathrm{yr}$. Conversion of $\dot{M}_{0}$ to strain rates with equation (3) gives

$$
\dot{\epsilon}_{i j}^{*}=\left[\begin{array}{rrr}
1.6 & -2.7 & 1.3 \\
0.6 & -1.0 & 0.5 \\
-0.8 & 1.4 & -0.7
\end{array}\right] \times 10^{-9} / \mathrm{yr} .
$$

The largest component is $\dot{\epsilon}_{12}^{*}=2.7 \times 10^{-9} / \mathrm{yr}$ and corresponds to about $0.6 \mathrm{~mm} /$ yr of right lateral shear, a result of the lateral component of slip on normal faults that trend at about $\mathrm{N} 30^{\circ} \mathrm{W}$. The oblique normal movement assumed for the two events in this region may further be resolved into an easterly contraction and a northerly extension. The $\dot{\epsilon}_{11}$ component equals $1.6 \times 10^{-9} / \mathrm{yr}$, corresponding to about $0.7 \mathrm{~mm} / \mathrm{yr}$ north-south extention across the region. The component of $\dot{\epsilon}_{22 a}^{*}=-1.0$ $\times 10^{-9} / \mathrm{yr}$ is equivalent to about $0.2 \mathrm{~mm} / \mathrm{yr}$ east-west contraction across the region. Little credence can be given to these figures since they are extrapolated from the occurrence of only two earthquakes.

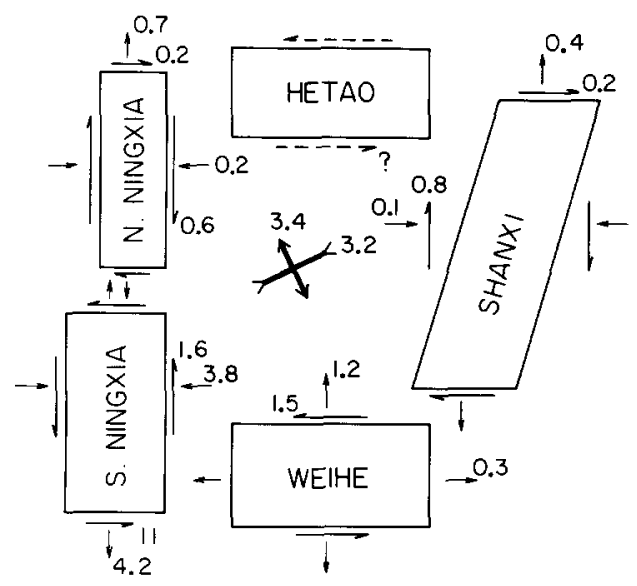

FIG. 5. Schematic illustration of the components of horizontal deformation that characterize the Ordos region of northeast China. Shear (half-sided arrows) and contractional (arrows) components of deformation are given in millimeters/year.

Weihe. The seismic moment release in Weihe averaged over the last $700 \mathrm{yr}$ is about $1.1 \times 10^{18} \mathrm{~N}-\mathrm{m} / \mathrm{yr}$. The strain rate for the region computed for the region with equation $(3)$ is

$$
\dot{\epsilon}_{i j}^{*}=\left[\begin{array}{rrr}
2.9 & 0.4 & -1.6 \\
-12.5 & 0.9 & 7.4 \\
6.5 & -0.4 & -3.8
\end{array}\right] \times 10^{-9} / \mathrm{yr} .
$$

The large value of $\dot{\epsilon}_{21}^{*}\left(-12.5 \times 10^{-9} / \mathrm{yr}\right)$ indicates that deformation is primarily occurring by left-lateral shear corresponding to about $2.5 \mathrm{~mm} / \mathrm{yr}$ of displacement across the region. The positive $\dot{\epsilon}_{11}^{*}$ and $\dot{\epsilon}_{22}^{*}$ components further indicate rates of north-south and east-west extensional strain equivalent to about 0.6 and $0.4 \mathrm{~mm} /$ $\mathrm{yr}$, respectively. The mode of deformation, as well as the rate, represented by these values is primarily influenced by the mechanism assumed for the great 1556 Huaxian earthquake. The $\dot{\epsilon}_{21}$ component ranges from 8.5 to $15.4 \times 10^{-9} / \mathrm{yr}$ if both 
the rake and dip are allowed to vary $\pm 15^{\circ}$ from the assigned values, and thus appears relatively insensitive to the assigned fault parameters. With similar variations in dip and rake, the $\epsilon_{12}^{*}$ component remains an order of magnitude less than $\dot{\epsilon}_{21}^{*}, \dot{\epsilon}_{22}^{*}$ changes by less than 20 per cent, and extreme values of $\dot{\epsilon}_{11}^{*}$ ranges from 0.3 to $5.5 \times 10^{-9} / \mathrm{yr}$. Finally, in accord with the normal mechanisms assumed for events in this region, $\epsilon_{333}$ is negative $\left(-3.8 \times 10^{-9} / \mathrm{yr}\right)$ and consistent with about $0.01 \mathrm{~mm} /$ yr crustal thinning of the 20 - $\mathrm{km}$-thick seismogenic layer.

The relatively large values of $\dot{\epsilon}_{13}^{*}=6.5 \times 10^{-9} / \mathrm{yr}$ and $\dot{\epsilon}_{23}^{*}=7.4 \times 10^{-9} / \mathrm{yr}$ is an artifact of the southward dip assumed for the mechanism of the 1556 earthquake and all other events in the region. Normal faults mapped in Weihe also show northdipping fault planes. It is reasonable to expect that, over longer periods of time, the normal faults that dip to the north will also rupture during earthquakes, in which case the $\dot{\epsilon}_{13}^{*}$ and $\dot{\epsilon}_{23}^{*}$ components would markedly decrease or disappear.

Shanxi. The rate of seismic moment release in Shanxi averaged over the last 700 yr is $\dot{M}_{0}=6.0 \times 10^{17} \mathrm{~N}-\mathrm{m} / \mathrm{yr}$. The strain rate tensor assessed for the region is

$$
\dot{\epsilon}_{i j}^{*}=\left[\begin{array}{rrr}
0.7 & -2.0 & -1.3 \\
-0.4 & -0.3 & -0.5 \\
0.7 & -0.9 & -0.4
\end{array}\right] \times 10^{-9} / \mathrm{yr} .
$$

The strain represented by the tensor corresponds to right-lateral normal displacements on faults that trend northeast. The components $\dot{\epsilon}_{11}^{*}=0.7 \times 10^{-9} / \mathrm{yr}$ and $\dot{\epsilon}_{12}^{*}$ $=-2.0 \times 10^{-9} / \mathrm{yr}$ are equivalent to about 0.4 and $0.8 \mathrm{~mm} / \mathrm{yr}$ of extension and rightlateral shear across the region, respectively (Figure 5). Variations in both the rake and dip as great as $\pm 15^{\circ}$ of all events yields changes of less than $50 \%$ in the $\epsilon_{11}^{*}$ and $\dot{\epsilon}_{12}$ components of strain. East-west contraction and right-lateral north-south shear equivalent to about 0.1 and $0.2 \mathrm{~mm} / \mathrm{yr}$ is further indicated by the $\epsilon_{22}^{*}\left(-0.3 \times 10^{-9}\right)$ and the $\dot{\epsilon}_{21}^{*}\left(-0.4 \times 10^{-9}\right)$ components of $\dot{\epsilon}_{i j}^{*}$. The components of $\dot{\epsilon}_{21}^{*}$ and $\dot{\epsilon}_{22}^{*}$ are found to change by up to 25 and 300 per cent, respectively, when the rake and dip of all events is varied over $\pm 15^{\circ}$. The normal component of offset associated with events in this area is consistent with crustal thinning, as indicated by the negative value of $\epsilon_{i: 3}$, of about $0.1 \mathrm{~mm} / \mathrm{yr}$ over the $20-\mathrm{km}$-thick volume.

The values of $\dot{\epsilon}_{13}^{*}, \dot{\epsilon}_{32}^{*}$, and $\dot{\epsilon}_{13}^{*}$ are relatively large because all events in this area are taken to occur on faults that dip northwest. Over longer recording periods it is likely that events also occur on the mapped faults in the graben system that dip to the southeast. In such case, these values of the tensor would markedly decrease or vanish.

\section{Discussion}

We have thus far presented results that describe the mode and rate of crustal deformation for the individual fault systems that bound the Ordos block. It is of equal interest to discuss the deformation of the region when considered as a single system. The moment release rate for the Ordos region averaged over the last $700 \mathrm{yr}$ is about $1.7 \times 10^{19} \mathrm{~N}-\mathrm{m} / \mathrm{yr}$. Displacements registered on faults along the margins of the Ordos block are consistent with a regional compressive stress system that trends northwest (Figure 5). The lateral component of fault displacements in Weihe, southern Ningxia and Hetao is right-lateral and, in a general sense, conjugate to that observed in northern Ningxia and Shanxi. The regional deformation resulting from earthquakes in all the regions examined is appropriately analyzed with equa- 
tion (2). Taking the Ordos region to be 1000 by $1000 \mathrm{~km}^{2}$, the average rate of crustal deformation of the area is consistently explained by an average $2.6 \times 10^{-9} / \mathrm{yr}$ contractional strain at $\mathrm{N} 70^{\circ} \mathrm{W}$ and $3.0 \times 10^{-9} / \mathrm{yr}$ of extensional strain oriented at $\mathrm{N} 160^{\circ} \mathrm{W}$. This corresponds to about 3 to $4 \mathrm{~mm} / \mathrm{yr}$ of both northwest contraction and northeast extension across the Ordos region.

A 700-yr record of seismicity provides the basis for our estimates of crustal deformation rates along the margins of the Ordos block. The question exists as to whether or not the rates determined from a 700 -yr period of time are representative of deformation rates over longer periods of time. Seismicity around the Ordos block during the last $700 \mathrm{yr}$ is shown as a plot of magnitude versus time in Figure 6 . The 100-year (open circles) and 350-yr (closed circles) running averages of the seismic

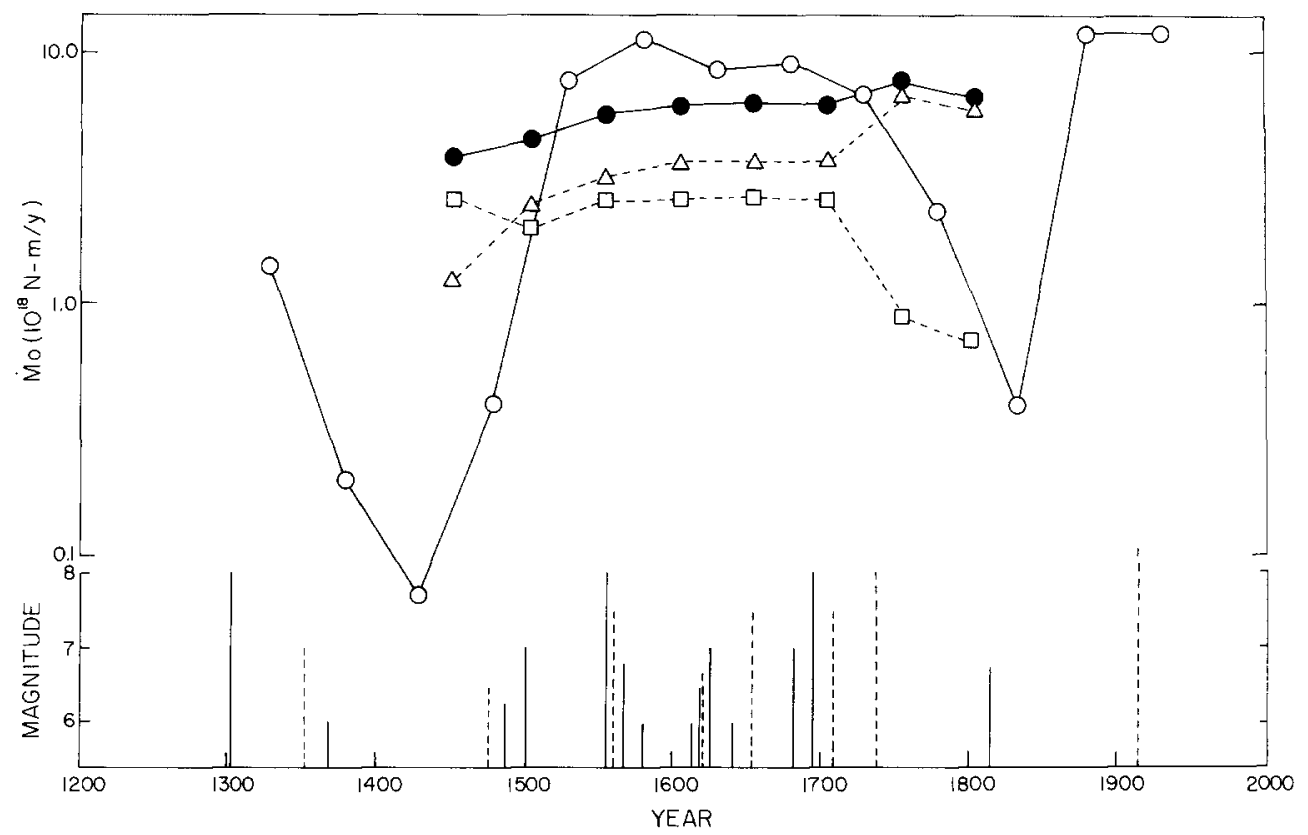

FIG. 6. The 700-yr record of seismicity along the margins of the Ordos block plotted as a function of magnitude versus time beneath 100-yr (open circles) and 350-yr (closed circles) running averages of $\dot{M}_{0}$, the rate of seismic moment release. The $350-y$ r running averages of $\dot{M}_{0}$ computed separately for the region including southern and northern Ningxia (triangles) and the area encompassing Weihe and Shanxi (squares) are also shown.

moment release rate, $\dot{M}_{0}$, are also plotted above the historical record of seismicity in Figure 6. The large variation in values of $\dot{M}_{0}$ in the 100 -yr curve and the observation that only one major event has occurred around the Ordos block in this century clearly shows that $100 \mathrm{yr}$ is an insufficient period to assess long-term rates of seismicity, and hence, rates of crustal deformation in this region. The $350-\mathrm{yr}$ curve, in contrast, shows much smaller fluctuations in $\dot{M}_{0}$. Periodicity in the occurrence of large earthquakes in eastern China has been documented but with periods on the order of $300 \mathrm{yr}$ (e.g., Deng et al., 1980), which is shorter than the time period covered in this study. Variations in seismicity over periods of time greater than that covered by the historical record cannot be ruled out. Until data describing the average rate of slip on Quaternary faults in the area are available, however, the 700 -year period sampled here provides the best possible means for estimating long-term crustal deformation rates in intraplate North China. 
The uncertainty associated with estimates of $\dot{M}_{0}$ and, hence, deformation rates, for the Ningxia, Weihe, and Shanxi regions is, of course, greater than when determined for the region as a whole. This results because the averages are being computed over smaller regions and is evidenced in Figure 6 by the larger fluctuations in running average curves of $\dot{M}_{0}$ computed for the area encompassing northern and southern Ningxia (triangles) and the combined area of Weihe and Shanxi (squares). $\dot{M}_{0}$ in the region consisting of north and south Ningxia, for example, is observed to increase with time. The increase may not be real but rather a result of missing historical data for the thirteenth and fourteenth centuries. This is quite possible since Ningxia lies farther from the ancient centers of civilization. The apparent increase of $\dot{M}_{0}$ in Ningxia is probably also enhanced by the occurrence in this century of the largest event ever recorded in this region (the 1920 Haiyuan earth-

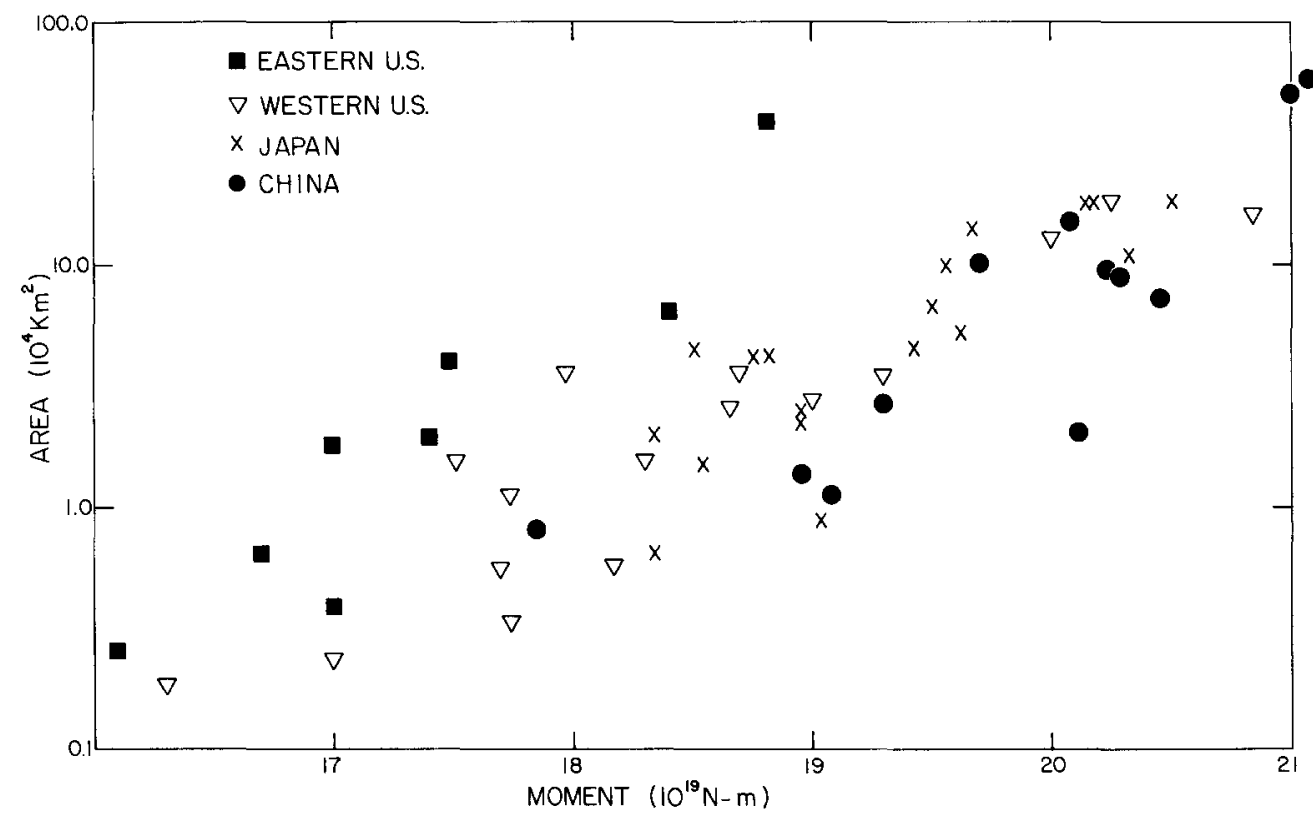

FIG. 7. Seismic moment versus the areal distribution of MM intensity VI for earthquakes in China (solid circles), Western United States (open triangles), Eastern United States (solid squares), and intraplate Japan (crosses).

quake, $\left.M_{0}=1.2 \times 10^{21} \mathrm{~N}-\mathrm{m}\right)$. For Shanxi and Weihe, the running average of $\dot{M}_{0}$ is relatively flat except for a steep drop during the most recent period. If, in fact, the flat portion of the curve is representative of long-term rates, the recent drop suggests that a large earthquake is due in the Shanxi-Weihe region, but this interpretation is quite speculative and difficult, if not impossible, to evaluate.

It is also of interest here to compare the relation of $M_{0}$ to the areal distribution of seismic intensity obtained in China to that observed in other regions of the world. The correlation between felt area of MM intensity VI and $M_{0}$ has been examined for portions of the eastern and western United States by Herrmann et al. (1978) and Hanks et al. (1975), respectively. Wesnousky et al. (1982) compared $M_{0}$ to felt area of the Japanese Meterological Agency's (JMA) intensity IV for intraplate earthquakes in Japan. JMA intensity IV is approximately equivalent to MM intensity VI (Trifunac and Brady, 1975). The results of each of the studies is reproduced in Figure 7 . It can be observed that, for the other regions, $M_{0}$ correlates 
with felt area of MM intensity VI as well as or better than it does in China. The systematic relation between $M_{0}$ and felt area of MM intensity VI remains when the data for each of the four regions are observed collectively, but the scatter is significantly greater. A relation developed between $M_{0}$ and felt area of intensity developed for one particular region should thus not be applied arbitrarily in another region. This ought to be expected since the distribution of isoseismals may be affected on a broad scale by a myriad of variables such as crustal structure (attenuation), standards of construction, and earthquake source parameters (e.g., depth and stress drop), all of which may vary in a consistent fashion from region to region.

\section{ACKNOWLEDGMENTS}

Paul Richards and David Simpson provided critical reviews of the manuscript. We thank Peter Molnar for advice and for providing several preprints of his work. The research was supported by NSF Contract CEE 82-06853.

\section{REFERENCES}

Aki, M. (1966). Generation and propagation of $G$ waves from the Niigata earthquake of June 16, 1964, part II. Bull. Earthquake Res. Inst., Univ. of Tokyo, 44, 73-88.

Aki, K. and P. G. Richards (1980). Quantitative Seismology: Theory and Methods, W. H. Freeman, San Francisco, California.

Chinese Academy of Sciences, Institute of Geophysics (1970). Catalogue of Chinese Earthquakes, Academia Sinica Press, Beijing, 2 vols., 361 pp. (in Chinese).

Chinese Area of Earthquake Intensity Study Group (1976). Atlas of Isointensity Maps for Chinese Earthquakes, Seismology Press, Beijing, 107 pp. (in Chinese).

Deng, Q. (1984). Holocene and Quaternary development and motion of the graben systems bounding the Ordos Block, in Seismology and Geology (in Chinese) (in press).

Deng, Q. and F. Fan (1980). Cenozoic and recent geotectonic characteristics of North China fault block region, in Formation and Development of North China Fault Block Region, Science Press, Beijing, 192-205 (in Chinese).

Deng, Q., K. Wang, Y. Wang, H. Tang, Y. Wu, and M. Ding (1973). On the tendency of seismicity and their geological set-up of the seismic belt of Shanxi Graben, Sci. Geol. Sin. 1, 37-47.

Deng, Q., Y. Chang, K. Hsu, and F. Fan (1979). On the tectonic stress field in China and its relation to plate movement, Phys. Earth Planet. Interiors 18, 257-273.

Deng, Q., Y. Zhang, W. Huan, H. Zhang, G. Xu, Y. Liu, R. Deng, Q. Li, F. Fan, and T. Yang (1980). Principles and methods of composing the seismic zoning map of China, J. Seismology 2, 90-110.

Deng, Q., Y. Chen, J. Wang, P. Jiang, Y. Wang, J. Xiang and C. Wang (1982). Some seismotectonic features of the North China fault block region and their dynamic model, Presented at the International Symposium on Continental Seismicity and Earthquake Prediction, Beijing.

Deng, Q., F. Sung, S. Zhu, M. Li, T. Wang, W. Zhang, B. C. Burchfiel, P. Molnar, and P. Zhang (1984). Active faulting and tectonics of the Ningxia-Hui Autonomous Region, China, J. Geophys. Res. 89, $4427-4446$.

Deng, Q. and Z. You (1984). The study of fault scarps and the estimation of seismic risk, with the JialenShandonglin fault scarp as an example, Seismology and Geology (in Chinese) (in press).

Gilbert, F. (1970). Excitation of the normal modes of slip along major fault zones, Geophys. J. R. Astr. Soc. 22, 223-226.

Hanks, T. C., J. A. Hileman, and W. Thatcher (1975). Seismic moments of the larger earthquakes of the southern California region, Geol. Soc. Am. Bull. 86, 1131-1139.

Herrmann, R. B., S. Cheng, and O. W. Nuttli (1978). Archeoseismology applied to the New Madrid earthquakes of 1811-1812, Bull. Seism. Soc. Am. 68, 1751-1760.

Institute of Geology, State Seismology Bureau (1979). Seismogenic Tectonics Map of the People's Republic of China, State Map Publishers, Beijing.

Kostrov, B. V. (1974). Seismic moment and energy of earthquakes, and seismic flow of rock, Izu. Acad. Sci. USSR Phys. Solid Earth 1, 23-40. 
Lee, W. H. K., F. T. Wu, and C. Jackson (1976). A catalog of historical earthquakes in China, Bull. Seism. Soc. Am. 66, 2003-2016.

Liao, Y. and Z. Pan (1982). Dislocation of the Great Wall in the Honggoujigou, Ningxia-Hui Autonomous Region (in Chinese), Seismology and Geology 4, 77-79.

Molnar, P. (1983). Average regional strain due to slip of numerous faults of different orientations, $J$. Geophys. Res. 88, 6430-6432.

Molnar, P. and P. Tapponier (1975). Cenozoic tectonics of Asia: effects of a continental collision, Science $189,419-426$.

Molnar, P. and P. Tapponier (1977a). Relation of the tectonics of eastern China to the India-Eurasia collision: application of slip-line field theory to large-scale continental tectonics, Geology 5, 212216.

Molnar, P. and P. Tapponier (1977b). The collision between India and Eurasia, Scientific American, 3041, April.

Molnar, P. and Q. Deng (1984). Faulting associated with large earthquakes and the average rate of deformation in Central and Eastern Asia, J. Geophys. Res. 89, 6203-6228.

Tapponier, P. and P. Molnar (1976). Slip-line field theory and large scale continental tectonics, Nature 264, 319-324.

Tapponier, P. and P. Molnar (1977). Active faulting and tectonics in China, J. Geophys. Res. 82, 29052930.

Trifunac, M. D. and A. G. Brady (1975). On the correlation of seismic intensity scales with the peaks of recorded strong ground motion, Bull. Seism. Soc. Am. 65, 139-162.

Wesnousky, S. G., C. H. Scholz, and K. Shimazaki (1982). Deformation of an island arc: rates of moment release and crustal shortening in intraplate Japan determined from seismicity and Quaternary fault data, J. Geophys. Res. 87, 6829-6852.

LAMONT-DOHERTY GEOLOGICAL OBSERVATORY OF COLUMBIA UNIVERSITY

INSTITUTE OF GEOLOGY

State Seismology Bureau

Palisades, New YoRk 10964 (S.G.W., L.M.J., C.H.S.) BeiJing, People's Republic of China (Q.D.)

CONTRibution No. 3686

STate Seismology Bureau

Manuscript received 7 November 1983 